15. Tilleman TR, Richards WG, Zellos L, Johnson BE, Jaklitsch MT, Mueller J, et al. Extrapleural pneumonectomy followed by intracavitary intraoperative hyperthermic cisplatin with pharmacologic cytoprotection for treatment of malignant pleural mesothelioma: a phase II prospective study. J Thorac Cardiovasc Surg. 2009;138:405-11.
16. Sugarbaker DJ, Flores RM, Jaklitsch MT, Richards WG, Strauss GM, Corson JM, et al. Resection margins, extrapleural nodal status, and cell type determine postoperative long-term survival in trimodality therapy of malignant pleural mesothelioma: results in 183 patients. J Thorac Cardiovasc Surg. 1999;117:54-63; discussion 63-5.
See Article page 1510.

\section{Commentary: Acute kidney injury after intrapleural cisplatin: Minimizing collateral damage}

\author{
Michael I. Ebright, MD
}

Malignant pleural mesothelioma (MPM) is perhaps one of the most vexing problems facing thoracic surgeons. Hyperthermic intraoperative cisplatin chemotherapy (HIOC) is an adjunctive option for patients undergoing cytoreductive surgery. The feasibility and safety of HIOC has been established, although a clear benefit has never been definitively proven. ${ }^{1}$ Cisplatin administered within the pleura has significant systemic absorption, which is known to injure the renal tubules and cause direct cytotoxicity.

In this issue of the Journal, Hod and colleagues ${ }^{2}$ report a retrospective observational study of their institutional prospectively maintained database for patients undergoing surgical therapy for MPM, hypothesizing that HIOC contributes to the incidence of acute kidney injury (AKI). A total of 503 patients underwent either extrapleural pneumonectomy $(\mathrm{n}=241)$ or pleurectomy/decortication $(\mathrm{n}=262)$ over a 9-year period. HIOC was administered to 312 patients.

Remarkably, more than $50 \%$ of the patients who received HIOC developed AKI. Ostensibly, this seems to represent

From the Section of Thoracic Surgery, Columbia University Medical Center, New York, NY.

Disclosures: The author reports no conflicts of interest.

The Journal policy requires editors and reviewers to disclose conflicts of interest and to decline handling or reviewing manuscripts for which they may have a conflict of interest. The editors and reviewers of this article have no conflicts of interest.

Received for publication June 23, 2020; revisions received June 23, 2020; accepted for publication June 24, 2020; available ahead of print July 12, 2020.

Address for reprints: Michael I. Ebright, MD, Section of Thoracic Surgery, Columbia University Medical Center, 161 Fort Washington Ave, 3rd Floor, New York, NY 10032 (E-mail: mie2110@ cumc.columbia.edu).

J Thorac Cardiovasc Surg 2021;161:1522-3

$0022-5223 / \$ 36.00$

Copyright (c) 2020 by The American Association for Thoracic Surgery

https://doi.org/10.1016/j.jtcvs.2020.06.095
Check for updates

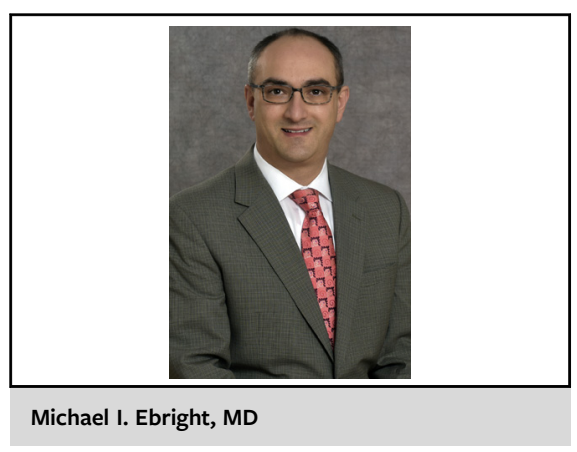

CENTRAL MESSAGE

Hyperthermic intraoperative cisplatin has significant renal toxicity and a fragile survival benefit. Its use should be avoided in patients at elevated risk of even mild acute kidney injury.

an unacceptably high risk for a therapy with unproven benefit. Approximately $25 \%$ of the patients who did not receive HIOC also developed AKI.

AKI was described using the Kidney Disease Improving Global Outcomes (KDIGO) definition, composed of 3 stages. KDIGO stage I is met when serum creatinine ( $\mathrm{SCr}$ ) rises by $0.3 \mathrm{mg} / \mathrm{dL}$ (or $50 \%-99 \%$ ) over baseline. Stage II is moderate AKI, and stage III is severe $\mathrm{AKI}$ and includes all patients who require renal replacement therapy. Of the patients developing AKI, 78\% were classified as the seemingly benign KDIGO stage I. Risk factors for AKI included male sex, HIOC, previous cisplatin exposure, hypertension, and longer operative time.

It should be mentioned that KDIGO stage I might not even be recognized as AKI during routine postoperative care, given that the SCr level may fall within the normal laboratory reference range. Stage I is generally not alarming to surgeons or nephrologists. So why do we care? Might this study, which proclaims a surprisingly high 
rate of acute tubular necrosis after HIOC, be much ado about nothing?

At the other extreme, 22 patients developed KDIGO stage III. Sixteen of these patients required dialysis, each of whom had received HIOC. It is clearly demonstrated that HIOC is associated with renal injury; however, it is known that even small increases in $\mathrm{SCr}$ are important and associated with a higher mortality rate.

Although not a primary endpoint of the study, survival was also evaluated. Patients who received HIOC had a lower risk of death but a higher risk of AKI. So do we consider the kidneys to be collateral damage while waging a difficult battle? The benefit of HIOC was nullified in the patients who developed AKI-including those with KDIGO stage I. Conversely, improved survival was enjoyed by those who received HIOC but avoided AKI.
HIOC is an adjunctive therapy with significant toxicity given to patients who are concurrently sustaining the risk of a relatively morbid operation. We must be very selective in its use. The authors stress the importance of prevention and early recognition of AKI. It may be more impactful and strategic to avoid HIOC altogether in patients at elevated risk for even mild AKI.

\section{References}

1. Richards WG, Zellos L, Bueno R, Jaklitsch MT, Janne PA, Cirieac LR, et al. Phase I to II study of pleurectomy/decortication and intraoperative intracavitary hyperthermic cisplatin lavage for mesothelioma. J Clin Oncol. 2006;24:1561-7.

2. Hod T, Fredberg K, Motwani SS, Chen M, Frendl G, Leaf DE, et al. Acute kidney injury after cytoreductive surgery and hyperthermic intraoperative cisplatin chemotherapy for malignant pleural mesothelioma. J Thorac Cardiovasc Surg. 2021;161:1510-8.

3. Chertow GM, Burkick E, Honour M, Bonventre JV, Bates DW. Acute kidney injury, mortality, length of stay, and costs in hospitalized patients. J Am Soc Nephrol. 2005; 16:3365-70. 